\title{
Fuzzy PID Control for Networked Control System of DC Motor with Random Design
}

\author{
Kota Bala Murali Krishna \\ Research Scholar \\ Dept of Physics \\ Acharya Nagarjuna University
}

\author{
B.V.S. Goud \\ HOD, EIE \\ Science Instrumentation Centre \\ Acharya Nagarjuna University
}

\begin{abstract}
Separately excited DC motor speed can be controlled using PID controller and fuzzy logic controller. The proportional, integral and derivate (KP, KI, KD) gains of the PID controller are adjusted according to FUZZY LOGIC. First, the fuzzy logic controller is designed according to fuzzy rules so that the systems are fundamentally robust. There are 25 fuzzy rules for self-tuning of each parameter of PID controller. The FLC has two inputs. One is the motor speed error between the reference and actual speed and the second is change in speed error (speed error derivative).Secondly, the output of the FLC i.e. the parameters of PID controller are used to control the speed of the separately excited DC Motor. The study shows that both precise characters of PID controllers and flexible characters of fuzzy controller are present in fuzzy self-tuning PID controller. The fuzzy self-tuning approach implemented on a conventional PID structure was able to improve the dynamic as well as the static response of the system. Comparison between the conventional output and the fuzzy self-tuning output was done on the basis of the simulation result obtained by MATLAB. The simulation results demonstrate that the designed self-tuned PID controller realize a good dynamic behavior of the DC motor, a perfect speed tracking with less rise and settling time, minimum overshoot, minimum steady state error and give better performance compared to conventional PID controller.
\end{abstract}

\section{INTRODUCTION}

The development of high performance motor drives is very important in industrial as well as other purpose applications such as steel rolling mills, electric trains and robotics. Generally, a high performance motor drive system must have good dynamic speed command tracking and load regulating response to perform task. DC drives, because of their simplicity, ease of application, high reliabilities, flexibilities and favorable cost have long been a backbone of industrial applications, robot manipulators and home appliances where speed and position control of motor are required. DC drives are less complex with a single power conversion from $\mathrm{AC}$ to DC. Again the speed torque characteristics of DC motors are much more superior to that of AC motors. A DC motors provide excellent control of speed for acceleration and deceleration. DC drives are normally less expensive for most horsepower ratings. DC motors have a long tradition of use as adjustable speed machines and a wide range of options have evolved for this purpose. In these applications, the motor should be precisely controlled to give the desired performance. The controllers of the speed that are conceived for goal to control the speed of DC motor to execute one variety of tasks, is of several conventional and numeric controller types, the controllers can be: proportional integral (PI), proportional integral derivative (PID) Fuzzy Logic Controller (FLC) or the combination between them: FuzzyNeural Networks, Fuzzy-Genetic Algorithm, Fuzzy-Ants Colony, Fuzzy-Swarm[10]. The proportional - integral derivative (PID) controller operates the majority of the control system in the world. It has been reported that more than $95 \%$ of the controllers in the industrial process control applications are of PID type as no other controller match the simplicity, clear functionality, applicability and ease of use offered by the PID controller [3], [4]. PID controllers provide robust and reliable performance for most systems if the PID parameters are tuned properly.

The major problems in applying a conventional control algorithm (PI, PD, PID) in a speed controller are the effects of non-linearity in a DC motor. The nonlinear characteristics of a DC motor such as saturation and fiction could degrade the performance of conventional controllers [1], [2].Generally, an accurate nonlinear model of an actual DC motor is difficult to find and parameter obtained from systems identification may be only approximated values. The field of Fuzzy control has been making rapid progress in recent years. Fuzzy logic control (FLC) is one of the most successful applications of fuzzy set theory, introduced by L.A Zadeh in 1973 and applied (Mamdani 1974) in an attempt to control system that are structurally difficult to model.

Since then, FLC has been an extremely active and fruitful research area with many industrial applications reported [5].In the last three decades, FLC has evolved as an alternative or complementary to the conventional control strategies in various engineering areas. Fuzzy control theory usually provides non-linear controllers that are capable of performing different complex non-linear control action, even for uncertain nonlinear systems. Unlike conventional control, designing a FLC does not require precise knowledge of the system model such as the poles and zeroes of the system transfer functions. Imitating the way of human learning, the tracking error and the rate change of the error are two crucial inputs for the design of such a fuzzy control system [6], [7]. 


\section{SPEED CONTROL OF SEPARATELY EXCITED DC MOTOR}
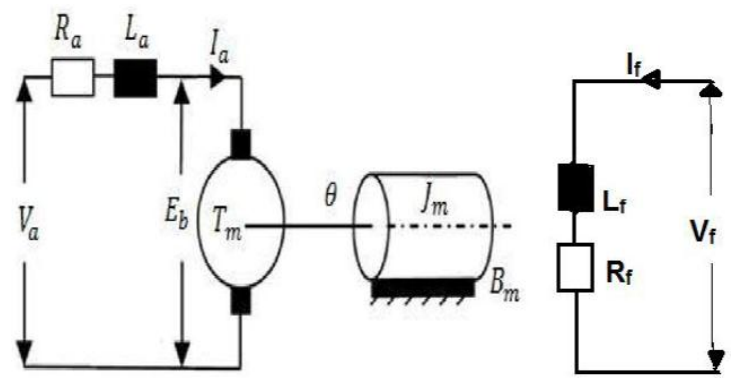

Fig 1: Model of DC Separately Excited Motor

DC motors are most suitable for wide range speed control and are there for many adjustable speed drives. Intentional speed variation carried out manually or automatically to control the speed of DC motors.

$\omega \alpha(\mathrm{Va}-\mathrm{IaRa}) / \phi$

$\omega=(\mathrm{Va}-\mathrm{IaRa}) / \mathrm{Ka} \phi$

Where $\phi=$ Field flux per pole

$\mathrm{Ka}=$ Armature constant $=\mathrm{PZ} / 2 \pi \mathrm{a}$

Where $\mathrm{P}=$ No. of poles, $\mathrm{Z}=$ Total no. of armature conductor, $\mathrm{a}$ $=$ No. of parallel path

From the equation (1) it is clear that for DC motor there are basically 3 method of speed control.

They are:-

1- Variation of resistance in armature circuit.

2- Variation of field flux.

3- Variation of armature terminal voltage.

\section{MODELING OF SEPARATELY EXCITED DC MOTOR}

From fig.1The armature voltage equation is given by:

$\mathrm{Va}=\mathrm{Eb}+\mathrm{IaRa}+\mathrm{La}(\mathrm{dIa} / \mathrm{dt})$

Now the torque balance equation will be given by

$\mathrm{Tm}=\mathrm{Jmd} \omega / \mathrm{dt}+\mathrm{Bm} \omega+\mathrm{TL}----\mathrm{I}$

Taking field flux as $\Phi$ and Back EMF Constant as K.

Equation for back emf of motor will be

$\mathrm{E}_{\mathrm{b}}=\mathrm{K} \phi \omega------\mathrm{II}$

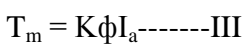

Taking laplace transform of the motor"s armature voltage equation

$\mathrm{Ia}(\mathrm{S})=(\mathrm{Va}-\mathrm{Eb}) /(\mathrm{Ra}+\mathrm{LaS})$

Now, taking equation (ii) into consideration, we have:

$\mathrm{Ia}(\mathrm{s})=(\mathrm{Va}-\mathrm{K} \Phi \omega) / \mathrm{Ra}(1+\mathrm{LaS} / \mathrm{Ra})$

And $\omega(\mathrm{s})=(\mathrm{Tm}-\mathrm{TL}) / \mathrm{JS}=(\mathrm{K} \Phi \mathrm{Ia}-\mathrm{TL}) / \mathrm{JmS}$

(Armature Time Constant) $\mathrm{Ta}=\mathrm{La} / \mathrm{Ra}$

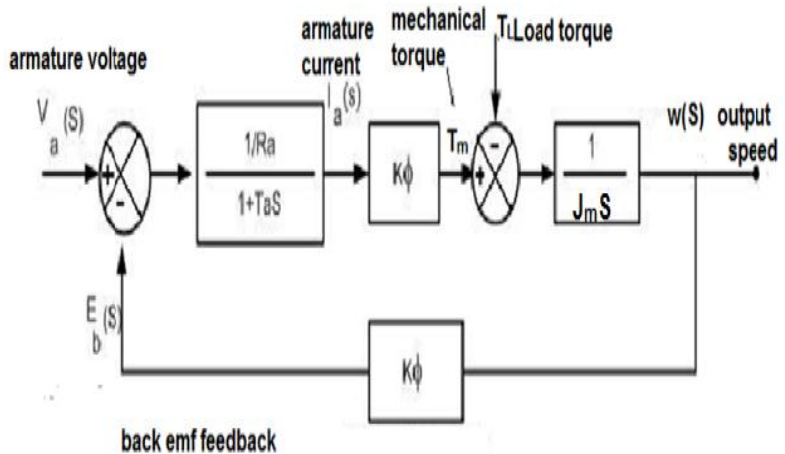

Fig 2: Modelling Block diagram of DC Separately Excited Motor

After simplifying the above motor model, the overall transfer function will be

$\omega(\mathrm{s}) / \mathrm{Va}(\mathrm{s})=[\mathrm{K} \Phi / \mathrm{Ra}] / \mathrm{JmS}(1+\mathrm{TaS}) /\left[1+\left(\mathrm{K}^{2} \Phi^{2} / \mathrm{Ra}\right)\right.$ $/ \mathrm{JmS}(1+\mathrm{TaS})]$

$\mathrm{Tm}=\mathrm{Jmd} \omega / \mathrm{dt}=\mathrm{K} \Phi \mathrm{Ia}$

$\omega(\mathrm{s})=\left[(\mathrm{Ra} / \mathrm{Km}) \mathrm{Ia}(\mathrm{s})-\mathrm{TL} \mathrm{Ra} /(\mathrm{Km})^{2}\right](1 / \mathrm{Tem}(\mathrm{s}))$

Now, Replacing K $\Phi$ by $\mathrm{Km}$ in equation (v), we will get: $\omega(\mathrm{s}) / \mathrm{Va}(\mathrm{s})=(1 / \mathrm{Km}) /\left(1+\mathrm{STem}+\mathrm{S}^{2} \mathrm{TaTem}\right)$

The armature time constant $\mathrm{Ta}$ is very much less than the electromechanical time constant Tem, $(\mathrm{Ta}<<\mathrm{Tem})$

Simplifying, $1+$ STem $+\mathrm{S}^{2}$ TaTem $\approx 1+\mathrm{S}(\mathrm{Ta}+\mathrm{Tem})+$ $\mathrm{S}^{2} \mathrm{TaTem}=(1+\mathrm{STem})(1+\mathrm{STa})$

The equation can be written as:

$\omega(\mathrm{s}) / \mathrm{Va}(\mathrm{s})=(1 / \mathrm{Km}) /((1+\mathrm{STem})(1+\mathrm{STa}))$

Tem and Ta are the time constants of the above system transfer function which will determine the response of the system. Hence the dc motor can be replaced by the transfer function obtained in above equation in the DC drive model.

Table 1. Parameters of the separately excited DC Motor

\begin{tabular}{|l|l|}
\hline Description of the parameter & Parameter value \\
\hline Armature resistance (Ra) & $0.5 \Omega$ \\
\hline Armature inductance (La) & $0.02 \mathrm{H}$ \\
\hline Armature voltage (Va) & $200 \mathrm{~V}$ \\
\hline Mechanical inertia (jm) & $0.1 \mathrm{Kg} . \mathrm{m} 2$ \\
\hline Friction coefficient (Bm) & $0.008 \mathrm{~N} . \mathrm{m} / \mathrm{rad} / \mathrm{sec}$ \\
\hline Back emf constant (k) & $1.25 \mathrm{~V} / \mathrm{rad} / \mathrm{sec}$ \\
\hline Rated speed & $1500 \mathrm{r} . \mathrm{p} . \mathrm{m}$ \\
\hline Motor torque constant & $1 \mathrm{~N} . \mathrm{m} / \mathrm{A}$ \\
\hline
\end{tabular}




\section{Fuzzy Logic Controller}

Fuzzy systems are knowledge based or rule based systems. The heart of a fuzzy system is a knowledge base consisting of the so- called If-Then rules. A fuzzy If-Then statement in which some words are characterized by continuous membership functions. After defining the fuzzy sets and assigning their membership functions, rules must be written to describe the action to be taken for each combination of control variables. These rules will relate the input variables to the output variable using If-Then statements which allow decisions to be made. The If (condition) is an antecedent to the Then (conclusion) of each rule. Each rule in general can be represented in the following manner:

If (antecedent) Then (consequence).

For example:

If the speed of the car is high, then apply less force to the accelerator.

If pressure is high, then volume is small

A fuzzy logic controller has four main components as shown in Figure:

a) Fuzzification

b) Inference engine

c) Rule base

d) Defuzzification

In order to define fuzzy membership function, designers choose many different shapes based on their preference and experience. There are generally four types of membership functions used:

\section{1: Trapezoidal MF}

2: Triangular MF

3: Gaussian MF

4: Generalized bell MF

\section{Fuzzy controller}

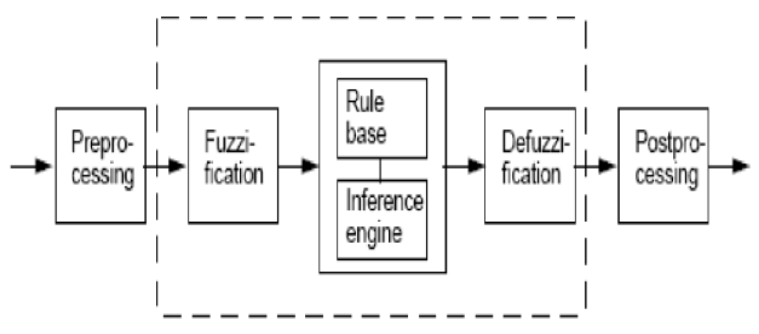

Fig 3: Structure of fuzzy logic controller

Implementation of an FLC requires the choice of four key factors

1: Number of fuzzy sets that constitute linguistic variables.

2: Mapping of the measurements onto the support sets.

3: Control protocol that determines the controller behavior.

4: Shape of membership functions.

PID parameters fuzzy self-tuning is to find the fuzzy relationship between the three parameters of PID and "e" and "de", and according to the principle of fuzzy control, to modify the three parameters in order to meet different requirements for control parameters when "e" and "de" are different, and to make the control object a good dynamic and static performance [12].

\subsection{Adjusting fuzzy membership functions and rules}

In order to improve the performance of FLC, the rules and membership functions are adjusted. The membership functions are adjusted by making the area of membership functions near ZE region narrower to produce finer control resolution. On the other hand, making the area far from ZE region wider gives faster control response. Also the performance can be improved by changing the severity of rules [15]. An experiment to study the effect of rise time (Tr), maximum overshoot $(\mathrm{Mp})$ and steady-state error (SSE) when varying $\mathrm{KP}, \mathrm{KI}$ and $\mathrm{KD}$ was conducted. The results of the experiment were used to develop 25-rules for the FLC of KP, $\mathrm{KI}$ and $\mathrm{KD}$ are the out put variables and from error and change of error are the input variables. Triangular membership functions are selected.

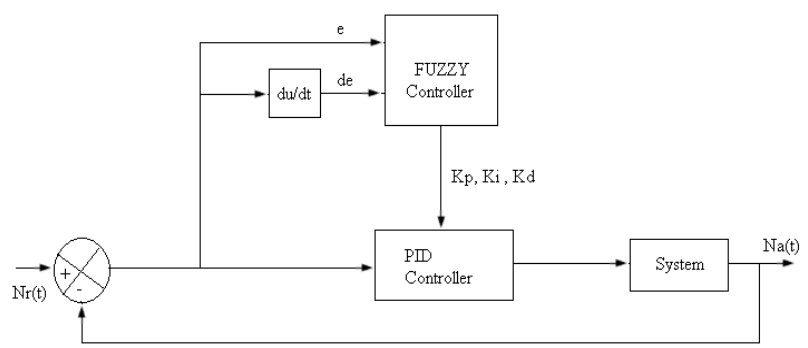

Fig 4: Block diagram of self-tuning fuzzy PID controller.

\subsection{Rule Base for PID parameters}

Table 2. Rule base for tuning KP Parameters

\begin{tabular}{|l|l|l|l|l|l|}
\hline de & NL & NS & ZE & PS & PL \\
\hline NL & PVL & PVL & PVL & PVL & PVL \\
\hline NS & PML & PML & PML & PL & PVL \\
\hline ZE & PVS & PVS & PS & PMS & PMS \\
\hline PS & PML & PML & PML & PL & PVL \\
\hline PL & PVL & PVL & PVL & PVL & PVL \\
\hline
\end{tabular}


Table 3. Rule base for tuning Ki

\begin{tabular}{|l|l|l|l|l|l|}
\hline de & NL & NS & ZE & PS & PL \\
\hline NL & PM & PM & PM & PM & PM \\
\hline NS & PMS & PMS & PMS & PMS & PMS \\
\hline ZE & PS & PS & PVS & PS & PS \\
\hline PS & PMS & PMS & PMS & PMS & PMS \\
\hline PL & PM & PM & PM & PM & PM \\
\hline
\end{tabular}

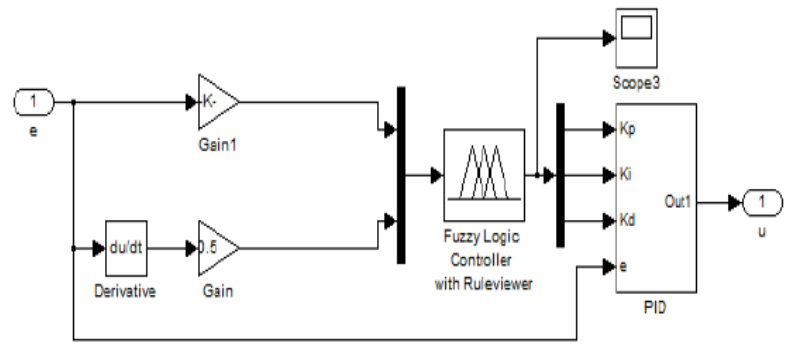

Fig 5: Simulink diagram of fuzzy-PID controller

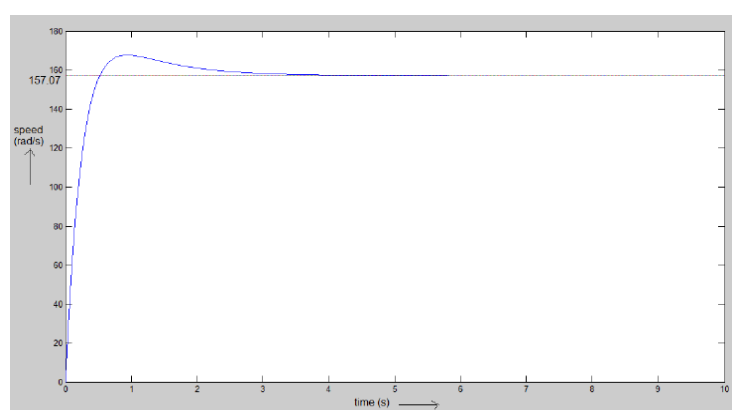

Fig75: Speed Vs time response of fuzzy tuned PID controlled DC motor.

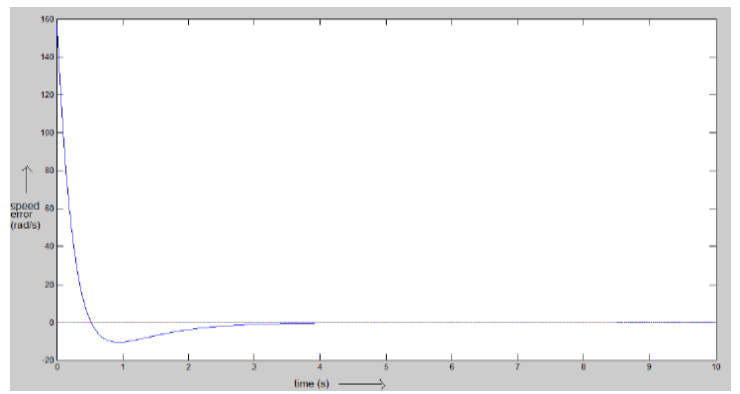

Fig 8: Error Vs time response of fuzzy tuned PID controlled DC motor.
Table 4. Rule base for tuning Kd

\begin{tabular}{|l|l|l|l|l|l|}
\hline de & NL & NS & ZE & PS & PL \\
\hline NL & PVS & PMS & PM & PL & PVL \\
\hline NS & PMS & PML & PL & PVL & PVL \\
\hline ZE & PM & PL & PL & PVL & PVL \\
\hline PS & PML & PVL & PVL & PVL & PVL \\
\hline PL & PVL & PVL & PVL & PVL & PVL \\
\hline
\end{tabular}

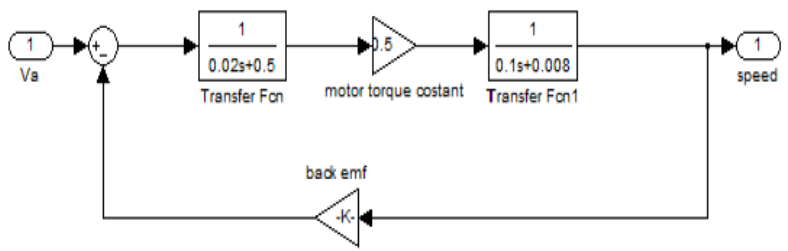

Fig 6: Simulink diagram of separately excited dc motor

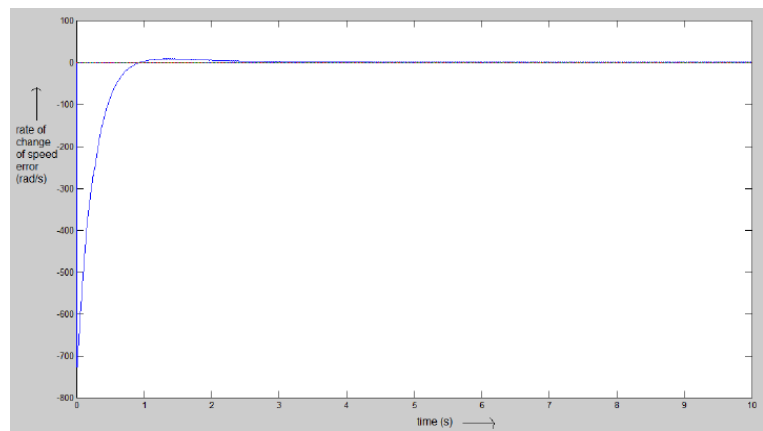

Fig 9: Change of speed Vs time response of fuzzy tuned PID controlled DC motor

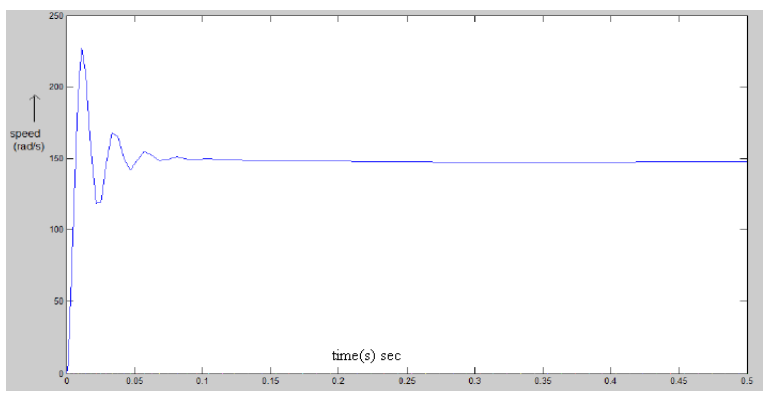

Fig 10: Speed Vs time response of PID controlled DC motor 


\section{CONCLUSION}

Self-tuned tuning PID controller is less in quality of operation and performance compared to conventional PID controller. The three parameters "KP", "KI", "KD" of conventional PID control need to be constantly adjust adjusted online in order to achieve better control performance. Fuzzy self-tuning PID parameters controller can automatically adjust PID parameters in accordance with the speed error and the rate of speed errorchange, so it has better self-adaptive capacity fuzzy PID parameter controller has smaller overshoot and less rising and settling time than conventional PID controller and has better dynamic response properties and steady-state properties. Steady state error in case of self tuned fuzzy PID is less compared to conventional PID controller.

Design method of two inputs and three outputs self-tuning fuzzy PID controller and make use of MATLAB fuzzy toolbox to design fuzzy controller. The fuzzy controller adjusted the proportional, integral and derivate (KP, KI, KD) gains of the PID controller according to speed error and change in speed error .From the simulation results it is concluded that ,compared with the conventional PID controller, self-tuning PID controller has a better performance in both transient and steady state response. The self tuning FLC has better dynamic response curve, shorter response time, small overshoot, small steady state error (SSE),high steady precision compared to the conventional PID controller.

\section{REFERENCES}

[1] B.J. Chalmers, "Influence of saturation in brushless permanent magnet drives." IEE proc. B, Electr.Power Appl, vol.139, no.1, 1992.

[2] C.T. Johnson and R.D. Lorenz, "Experimental identification of friction and its compensation in precise, position controlled mechanism." IEEE Trans. Ind ,Applicat, vol.28, no.6, 1992.

[3] Zhang, N. Wang and S. Wang, "A developed method of tuning PID controllers with fuzzy rules for integrating process," Proceedings of the American Control Conference,Boston, 2004, pp. 1109-1114.

[4] K.H. Ang, G. Chong and Y. Li, "PID control system analysis, design and technology," IEEE transaction on Control System Technology, Vol.13, No.4, 2005, pp. 559-576.

[5] H.X.Li and S.K.Tso, "Quantitative design and analysis of Fuzzy Proportional-Integral-Derivative Control- a
Step towards Auto tuning", International journal of system science, Vol.31, No.5, 2000, pp.545-553.

[6] Thana Pattaradej, Guanrong Chen and PitikhateSooraksa, "Design and Implementation of Fuzzy PID Control of a bicycle robot", Integrated computer-aided engineering, Vol.9, No.4, 2002

[7] Weiming Tang, Guanrong Chen and Rongde Lu, "A Modified Fuzzy PI Controller for a Flexible-joint Robot Arm with Uncertainties", Fuzzy Set and System, 118 (2001) 109-119.

[8] PavolFedor, Daniela Perduková, “A Simple Fuzzy Controller Structure,"ActaElectrotechnica ET Informatica No. 4, Vol. 5, 2005.

[9] Maher M.F. Algreer andYhyaR.M.Kuraz, "Design Fuzzy Self Tuning of PID Controller for Chopper-Fed DC Motor drive." Kuraz.

[10] BomedieneAlloua ,AbdellahLaoufBrahimGasbaoui and ABdessalamAbderrahamani, "Neuro-Fuzzy DC Motor speed Control Using Particle Swarm Optimization," Leonaro Electronic Journal of Practices and Technologies ISSN,1583-1078.

[11] ManafeddinNamazov and OnurBasturk, "DC motor position control using fuzzy proportional-derivative controllers with different defuzzification methods," Turkish Journal of Fuzzy Systems (eISSN: 1309-1190), Vol.1, No.1, pp. 36-54, 2010.

[12] Wang Xiao-kan, Sun Zhong-liang, Wanglei, Feng Dongqing, "Design and Research Based on Fuzzy PIDParameters Self-Tuning Controller with MATLAB," Advanced Computer Theory and Engineering, International Conference on, pp. 996-999, 2008 International Conference on Advanced Computer Theory and Engineering, 2008.

[13] GaddamMallesham and AkulaRajani ,"AUTOMATIC TUNING OF PID CONTROLLER USING FUZZY LOGIC ." 8th International Conference on DEVELOPMENT AND APPLICATION SYSTEMS Suceava, Romania, May 25 - 27, 2006.

[14] M.Chow and A. Menozzi ,'on the comparison of emerging and conventional techniques for DC motor control” proc.IECON ,PP.1008-1013,1992. 